\title{
Virtually possible: using telehealth to bring reproductive health care to women with opioid use disorder in rural Maine
}

\author{
Terri-Ann Thompson ${ }^{1}$, Katherine A. Ahrens ${ }^{2}$, Leah Coplon ${ }^{3}$ \\ ${ }^{1}$ Ibis Reproductive Health, Cambridge, MA, USA; ${ }^{2}$ University of Southern Maine, Muskie School of Public Service, Portland, ME, USA; ${ }^{3}$ Maine \\ Family Planning, Augusta, ME, USA \\ Contributions: (I) Conception and design: All authors; (II) Administrative support: None; (III) Provision of study materials or patients: None; (IV) \\ Collection and assembly of data: L Coplon; (V) Data analysis and interpretation: TA Thompson, KA Ahrens; (VI) Manuscript writing: All authors; \\ (VII) Final approval of manuscript: All authors. \\ Correspondence to: Terri-Ann Thompson, PhD. Ibis Reproductive Health, 2067 Massachusetts Avenue, Suite 320, Cambridge, MA 02140, USA. \\ Email: tthompson@ibisreproductivehealth.org.
}

Background: Maternal opioid use disorder (OUD) has increased more sharply in recent years among rural residents in the United States than among urban residents. In 2018, the prevalence of maternal OUD accounted for $3.5 \%$ of all hospital deliveries in Maine. Opioid use during pregnancy is associated with negative health effects for both the woman and infant. While many women with OUD use contraception, few report using a highly reliable method.

Methods: A family planning clinic in Maine piloted a program to increase reproductive health access for women with OUD through the use of telehealth. In this model, a community outreach educator travelled to a community organization that serves this population to provide reproductive health information and an opportunity to connect with a nurse practitioner via telehealth to receive the following reproductive health services: HIV counseling and testing, contraception, or pregnancy testing and counseling. We assessed the feasibility of this program through the following outcome measures: number of women who engaged with the community outreach educator, number of women who used telehealth services, and number of women who received services at a referred clinic during the six-month pilot.

Results: During the pilot program, the community outreach educator held eighteen educational sessions and engaged fifty-one women; providing condoms and/or answers to various reproductive health questions. Fifteen women used telehealth services. The majority used the service to receive testing for sexually transmitted infections (STI) such as HIV. Four women used telehealth for contraceptive services and received either birth control or the Depo-Provera injectable on-site. A third of the women received more than one reproductive health service via telehealth. Of the women who were referred to a family planning clinic for additional services, only 2 attended their appointment. No challenges with hearing or seeing the practitioner through the video platform were recorded.

Conclusions: Improving women's access to effective contraceptive methods and preventive reproductive health services is critical to ensuring women with OUD are able to seek effective treatment and to ensure the health of future pregnancies. Findings from this pilot program suggest that innovative health care models such as on-site provision of reproductive health care through telehealth have the potential to increase access to reproductive care for this hard-to-reach population.

Keywords: Telehealth; opioid use disorder (OUD); family planning; reproductive health

Received: 26 November 2019; Accepted: 15 May 2020; Published: 05 October 2020.

doi: $10.21037 /$ mhealth-19-237

View this article at: http://dx.doi.org/10.21037/mhealth-19-237 


\section{Introduction}

The use of opioids and other substances has increased dramatically over the last decade in the rural state of Maine (1). In 2017, Maine had an age-adjusted rate of drug overdose deaths twice the rate in the United States (29.9 versus 14.9 per 100,000 standard population) (1). As the rate of drug overdose deaths has increased, so has the rate of deaths specific to opioid use; now accounting for nearly $85 \%$ of drug overdose deaths in the state in 2017 (2). While rate of deaths from opioids has increased at a slower pace for women than men in Maine, the rate for women is 1.5 times higher in Maine than in the United States (14.3 vs. 9.4 per 100,000 standard population) (1).

Opioid use disorder (OUD) carries serious potential consequences such as disability, relapse, and death for the user (3). For women, this disorder also bears consequences for reproductive health and for an infant born from a pregnancy where opioids were used. Prevalence of unintended pregnancy is substantially higher among opioid dependent women than in the general population with studies showing rates of unintended pregnancy among women with opioid and other substance use disorder (SUD) ranging from $67 \%$ to $86 \%$ (as opposed to $31 \%$ to $47 \%$ in the general population) (4-7). These pregnancies are concerning because of their association with poor maternal and child health outcomes, including poor developmental outcomes for children, risk of pre-term and low birth weight infants, and post-partum depression (8-10).

A multi-state analysis of hospital discharge data found the prevalence of maternal OUD at delivery hospitalization in Maine increased nearly fifty-fold since the late 1990s, from 0.7 per 1,000 delivery hospitalizations in 1999 to 34.1 per 1,000 in 2012, the second highest average annual increase among the states examined $(11,12)$. A more recent analysis found this rate to be 34.9 per 1,000 deliveries in 2018; meaning that one out of every 29 hospital deliveries $(3.5 \%)$ in Maine are among women with OUD documented in their hospital record (13). Further, women with OUD at delivery were more likely to experience mental health disorders, other substance use or dependence, and have a hepatitis $\mathrm{C}$ diagnosis than women without OUD. The cost to publicly funded health insurance programs and to families with a newborn exposed to opioids in utero is high as these newborns are more likely to have low birth weight and respiratory complications than other newborns (14).

Finally, women with OUD are at heightened risk for human immunodeficiency virus (HIV) acquisition and transmission because of high risk behaviors such as needle sharing, coercive relationships with men, and exchanging sex for drugs (15). While HIV prevalence among women overall in Maine is below the national average (53.6 vs. 169.9 per 100,000 women) (16), $28.4 \%$ of women living with HIV in Maine reported injection drug use as a potential route of transmission (2).

Meeting the reproductive health needs of people with opioid and other SUD is critical. However, extant literature suggests that reproductive health conversations are not common practice between providers and women with SUD. Results from a study of women with SUD receiving SUD treatment found that many were not being asked about family planning needs, were unable to fill prescriptions for birth control, had difficulty making and getting appointments with doctors outside of the treatment program, and were unaware that they could discuss reproductive health with staff at their treatment program (17). Additionally, a study of contraceptive prevalence among women in treatment for SUD found that although half were using contraception, only $20 \%$, were using a highly reliable method (17). Further, close to $85 \%$ of women reported that they would be more likely to use reproductive health services if they were offered through the treatment program (18).

\section{Challenges to getting care in Maine}

In comparison to other states dealing with rising opioid use, residents of Maine face different and significant barriers to getting medical, behavioral, and preventive health care. Maine is considered the most rural state in the US, with $61 \%$ of the population living in rural areas (19). Accessing care often entails substantial travel, which requires financial resources, the ability to miss work, dependable childcare, and reliable transportation. Barriers to health care access are particularly an issue in regard to reproductive health care; for example, 25 percent of women of reproductive age in Maine live in a county that lacks an abortion provider (20). Further, 64,000 reproductive age Maine women live in "contraceptive deserts", defined as places where women lack reasonable access to a health center with the full range of birth control methods available (21). In addition, across the United States, there is a shortage of women's healthcare providers. It is estimated that, by 2020 , the shortage will grow to a gap up to 8,800 obstetricians and gynecologists [out of 46,341 required (22)] and this gap will be most felt in rural areas (23). The majority of counties with the highest 
rates of OUD at delivery (5\% to $7 \%$ ) are rural counties in midcoast, central, and northern Maine, making geographic location a key barrier to accessing reproductive health care for this population (13).

Telehealth, "the use of electronic information and telecommunication technologies to facilitate the delivery of health-related information, education and services" (24), has grown in use as a health care model for providing care across long distances, in non-traditional facilities, and to underserved communities. The range of services that can be classified as telehealth is broad and includes patient-toprovider and provider-to-provider interactions as well as real-time interactions versus the transfer of information such as diagnostic images or videos from one site to another. Many health care services including mental health care, emergency medicine, and reproductive health care have expanded their reach through telehealth (25). Preliminary evidence on the use of telehealth to provide care has shown it to be effective across various health services (26-29), beneficial for special populations (e.g., children, military, and prison) (30-32), financially beneficial to doctors and hospitals (33), and acceptable to patients (34-36). Telehealth service use has increased substantially, growing by 960 percent between 2011 and 2016 in rural areas (37).

\section{Use of telehealth in reproductive bealth care}

Telehealth is being used for reproductive health care to overcome barriers to access and use. Evaluations of telehealth for contraception found that models such as text messaging can improve continuation of some contraceptive methods $(38,39)$. Evidence on the use of telehealth for medication abortion shows it to be safe and effective, as well as highly acceptable to patients and providers $(26,34,40)$. Telehealth is well suited for populations, such as those with OUD, who face internal and external barriers to care. A remote connection from the treatment program to a reproductive health specialist has the potential to address barriers to care. These include lowering potential feelings of stigma through fewer in-person visits and addressing low health care utilization by providing access to different types of care (including specialty care) in one location.

\section{Aim of the current study}

The serious health and economic consequences of unintended pregnancy among women with OUD make innovative reproductive service delivery models especially crucial for the health, safety, and success of women and their families. In this paper, we examine the feasibility of a program that aimed to help women with OUD in Maine meet their reproductive health needs by bringing services directly to them through the use of community outreach educators and telehealth. In this program, community outreach educators travelled to sites that offered services to persons with OUD and provided reproductive health services (family planning counseling and method provision, HIV/sexually transmitted infections (STI) counseling and testing, and pregnancy testing and options counseling) while connected to a nurse practitioner via telehealth.

\section{Methods}

\section{Population}

Participants in this pilot program were women between the ages of 18 and 50, who were attending a program that offered OUD-supportive services. For the purpose of this paper, we have broadly defined OUD-supportive services to include treatment, social, and preventive services. Eligible participants were residents of Maine who had insurance coverage through MaineCare (the Medicaid program in the state), Medicare, or private insurance, or were eligible to receive free or reduced cost services through the Title $\mathrm{X}$ program, a federal family planning program. Participation in the pilot program was voluntary, and women were not compensated financially or otherwise for their participation. The pilot program focused on women of reproductive age, as the ability to prevent an unintended pregnancy may critically influence their ability to seek effective treatment for OUD and improve the health of future pregnancies.

\section{Setting}

To access this stigmatized and often hard-to-reach population, the family planning clinic partnered with community organizations that serve women with OUD throughout the state of Maine. Organizations included domestic violence programs, harm-reduction programs, intensive outpatient programs, OUD treatment programs, needle exchange programs, and behavioral health organizations. By partnering with a diverse group of community organizations, the family planning clinic enhanced its chances of reaching a diverse group of women with OUD and reproductive health needs that could be served by the pilot program. Seven community organizations 


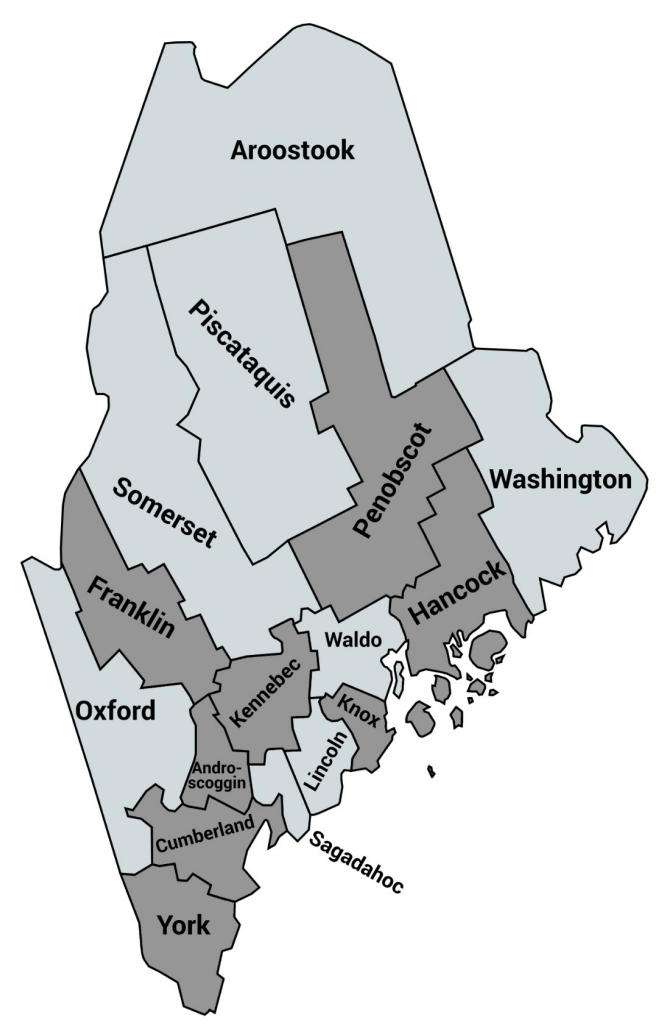

Figure 1 County locations for the 12 community organization sites: Androscoggin, Cumberland, Franklin, Hancock, Kennebec, Knox, Penobscot, and York.

spread across 12 sites participated in the pilot program. Sites were located in 8 counties in Maine (Figure 1). Included in this selection were the five counties with the highest rates of (I) hospital admissions involving substance use; (II) drug overdose deaths per 100,000 residents; (III) drug affected infant notifications to Maine's Office of Child and Family Services; and (IV) opiate poisoning emergency department rate per 10,000 in the state (41).

\section{Intervention}

The pilot program called "The Reproductive Empowerment Project”, was implemented between December 2018 and May 2019. This program paired the services of a family planning clinic with community organizations across multiple locations in Maine that provide services to women with OUD. The program was implemented as follows:

* A community outreach educator from the family planning clinic travelled to a site that offered OUDsupportive services. On average, each site received two visits per month. Prior to implementation, community outreach educators received training from the Portland Public Health Division on substance use and naloxone; in addition to other professional education and training on harm reduction frameworks, non-coercive contraception counseling, mandated reporting, and gender-based violence disclosure. Further, community outreach educators had general knowledge of clinical care.

* The community outreach educator held educational presentations on reproductive health inclusive of information on contraceptive methods, harm reduction strategies related to sexual behaviors, and STI/HIV transmission prevention. Educational sessions were done in group format and advertised through posters, by staff, and by the community outreach educators at recovery group sessions. All respondents who attended the educational sessions were made aware of the opportunity to receive onsite services for sexual and reproductive health care.

* The community outreach educator was given a private room, access to $\mathrm{Wi}-\mathrm{Fi}$ connection, and access to bathroom facilities to provide confidential one-on-one consultations with women who were interested in receiving care.

* During the consultation, the community outreach educator provided optional risk assessments and supplied internal and external condoms to any individual who requested them on-site.

* As part of the consultation, a woman could opt to be connected with a nurse practitioner via a secure, HIPAA-compliant video platform using the clinic's telehealth system.

* During the telehealth visit, a nurse practitioner could provide contraceptive counseling, discussing all contraceptive methods. Women who desired an oral or injectable birth control method were able to receive a prescription or the actual method from the community outreach educator.

- Women who desired a long-acting reversible contraceptive method (e.g., intrauterine device, implant) were given a referral to the nearest clinic site to arrange insertion. As part of the referral process, women were given appointment cards and a print-out with the location of the clinic. To streamline the clinic visit and help women feel 
Table 1 The Maine reproductive empowerment project pilot study feasibility questions and outcome measures

\begin{tabular}{ll}
\hline Feasibility Questions & Feasibility (outcome) measures \\
\hline $\begin{array}{l}\text { Will the target population engage with the community outreach } \\
\text { educator? }\end{array}$ & $\begin{array}{l}\text { Number of interactions the community outreach educator has with } \\
\text { target population } \\
\text { Will the target population use telehealth services? }\end{array}$ \\
$\begin{array}{ll}\text { Number of participants who have a telehealth visit } \\
\text { Can the telehealth services be delivered per the protocol? }\end{array}$ & $\begin{array}{l}\text { Number of participants who successfully receive reproductive health } \\
\text { services }\end{array}$ \\
$\begin{array}{ll}\text { What reproductive health services are used by the target } \\
\text { population? }\end{array}$ & $\begin{array}{l}\text { Types of reproductive health services provided over the six-month } \\
\text { period (referrals, contraceptive methods, preventive services, etc.) }\end{array}$ \\
Will the target population attend follow-up appointments? & $\begin{array}{l}\text { Number of participants who attend a follow-up appointment at a } \\
\text { referred clinic }\end{array}$ \\
$\begin{array}{l}\text { Will community organizations remain engaged throughout the } \\
\text { pilot study? }\end{array}$ & $\begin{array}{l}\text { Number of community organizations who discontinue from the pilot } \\
\text { program }\end{array}$
\end{tabular}

more connected, the community outreach educator assisted them in completing patient registration forms and financial agreements (to receive services at a reduced cost) ahead of the visit. Finally, women who provided contact information received at least one appointment reminder telephone call.

* Community outreach educators travelled with contraceptive supplies [oral pills and injectable birth control, condoms (internal and external)] and equipment to facilitate STI/HIV counseling and testing, and pregnancy testing and comprehensive options counseling (42) as ordered by the nurse practitioner.

* No other additional services, such as childcare or transportation were provided to pilot program participants.

The aim of the study was to determine the feasibility of the intervention, as described above, administered to an array of women seeking OUD-supportive services. With this study, we set out to answer the following feasibility questions using these outcome measures (Table 1). Descriptive analyses were used to analyze outcomes of interest from the six-month pilot program. Because these data were collected as part of routine service delivery data, aggregated, and de-identified prior to analysis, this work is not considered to be human subjects research (43).

\section{Results}

During the six-month pilot program, the community outreach educator held a total of 18 educational sessions across the 12 sites. Six sites had 2 educational sessions while the remainder had 1 educational session each during the 6-month period. Educational sessions were thirtyminute group discussions where information on a range of reproductive health topics such as contraception and STI/ HIV prevention were presented. Less frequently discussed topics such as reproductive coercion, healthy sexuality, and sexual consent were also presented. On average five women attended each session. In addition to these educational sessions, community outreach educators had informal oneon-one discussions with 51 women across the 12 sites. Many of these informal discussions emerged because women had reproductive health related questions or sought condoms.

A total of fifteen women opted to have a telehealth visit to receive reproductive health services. Telehealth patients were ages $22-50$ years, with a median age of 30 years. Telehealth patients were from five different community organization sites, and resided in three of the five counties most affected by SUD. Sixty percent of patients $(60 \%)$ resided in the Androscoggin County (Table 2). The majority (67\%) of patients used the telehealth visit to receive HIV/ STI counseling and testing services. Twenty-seven percent of the patients used the visit to receive a contraceptive method (oral pills or birth control injectable), while $47 \%$ received pregnancy testing and/or options counseling. Pregnancy options counseling occurred when a patient had a positive pregnancy test; a nurse practitioner (via telehealth) would discuss options for the pregnancy including abortion, parenting, adoption, and foster plan. Five of the fifteen patients used the telehealth visit to receive more than one type of reproductive health service. The most common combination of services was HIV/ STI counseling and testing with pregnancy testing and/or 
options counseling.

Of the fifteen women who had a telehealth visit, 5 were given referrals to and appointments made at a nearby family planning clinic. These appointments were made for other contraceptive services (e.g., to insert a long-acting reversible method) or for further evaluation and treatment of a sexual health issue. Two telehealth patients attended their followup appointment at the referred clinic (Table 3).

The protocol for delivering reproductive health services through telehealth was successful. All fifteen patients were able to receive one or more of the three reproductive health services offered and/or a referral to a nearby clinic for additional services. There were no reported issues related to hearing or seeing the nurse practitioner on the video screen, nor ethical issues that arose from having a community outreach educator on-site. Finally, there were

Table 2 The Maine reproductive empowerment project pilot study telehealth patient characteristics

\begin{tabular}{ll}
\hline Telehealth patient characteristics & $\mathrm{n}(\%)$ \\
\hline Age & Median: 30 years \\
County of residence & $3(20 \%)$ \\
Cumberland & $3(20 \%)$ \\
Kennebec & $9(60 \%)$ \\
Androscoggin & \\
Pregnancy history* & $2(18 \%)$ \\
Never pregnant & $3(27 \%)$ \\
Two or three pregnancies & $6(55 \%)$ \\
Four or more pregnancies &
\end{tabular}

${ }^{*}$ Eleven respondents reported on their pregnancy history. no community organizations who asked to be removed from the pilot program; in contrast, three new community organizations expressed an interest in joining the pilot program as a site.

\section{Discussion}

Findings from a study of a targeted reproductive outreach program for women receiving OUD-supportive services in Maine suggest that on-site provision of reproductive services through telehealth can facilitate reproductive health care utilization among this population. Further, the presence of a community outreach educator on-site can promote engagement with reproductive health information and method uses. Over the course of the program, the community outreach educator had 51 uninitiated interactions with women to address reproductive health questions and/or needs through condom provision. All reproductive health services offered through telehealth were utilized. HIV/STI counseling and testing was the most commonly utilized service suggesting that this health issue may be of particular concern for this population.

These preliminary results suggest that removing the barrier of making an appointment and traveling to a separate location for reproductive health services is beneficial to a community that may be reluctant to engage with the health care system. Reluctance to engage might stem from a mistrust of health professionals who may either stigmatize or misunderstand this community, and from characteristics of persons with OUD, who frequently experience "poor self-efficacy, chaotic lifestyles, and difficulty keeping appointments" (4). Individuals with opioid and other SUDs often have cooccurring health conditions like HIV (44), mood and

Table 3 Maine reproductive empowerment project pilot study, summary of outcomes (December 2018 through May 2019)

\begin{tabular}{ll}
\hline Variable & Number \\
\hline Women engaged through pilot program & 51 \\
Women receiving reproductive services via telehealth & 15 \\
Contraceptive methods received on-site & $\begin{array}{l}4: 27 \% \text { of telehealth patients received a contraceptive method on-site: Depo- } \\
\text { Provera }(\mathrm{n}=2) \text { and oral birth control }(\mathrm{n}=2)\end{array}$ \\
Referrals & $\begin{array}{l}5: 33 \% \text { of telehealth patients who spoke with a nurse practitioner were referred } \\
\text { for contraceptive methods }(\mathrm{n}=2) \text { or for further evaluation and treatment of a }\end{array}$ \\
& $\begin{array}{l}\text { sexual health issue }(\mathrm{n}=3) \\
2: 40 \% \text { of telehealth patients who received an appointment at a family planning } \\
\text { clinic attended the visit within } 6 \text { months }\end{array}$ \\
\hline
\end{tabular}


anxiety disorders (45), and cardiovascular disease (46) that impact not only life expectancy, but also quality of life. In a study of a residential integrated treatment model for mental health and OUDs, researchers observed a significant reduction in the number of emergency room visits, inpatient admissions, and health care utilization costs, in the six months that followed treatment (47). In other words, integrating care for these co-occurring disorders had an immediate impact on health and health service use. Based on that finding, several years ago the family planning clinic attempted to integrate OUD treatment services at their clinics- but this effort was met with little success as few persons took advantage of services at the clinic. The combined intervention of bringing reproductive health services to treatment, prevention, and/or social service programs through telehealth proved to be a more successful way to integrate care for these health conditions (OUD and reproductive health). The pilot program we described fulfilled two goals: that of meeting the reproductive health needs (such as HIV/STI counseling and testing) among this population and connecting women with OUD with a family planning clinic.

Further, our findings align with previous literature showing that in primary health care, delivering services within a harm reduction framework, in a way that is nonjudgmental, confidential, free of cost, and provided through a multidisciplinary team on a non-appointment basis enhances accessibility and acceptability of the services to people who inject drugs $(48,49)$. In a similar way, a community outreach educator being present at a site offering walk-in sexual health visits in a private location and/or sexual health information in a non-judgmental way could make sexual and reproductive health more accessible and acceptable to this population.

Telehealth was key to the success of this program. The use of a video platform provided nurse practitioners with greater access to this hard-to-reach population. The family planning clinic has been using telehealth for the last five years to provide reproductive health services to women throughout the state of Maine. As such, staff were well acquainted with the telecommunications system and to working with virtual patients. This translated into few technical issues during the telehealth visits and to an ease in building rapport quickly with patients who are at a distance. Other key components of this pilot program's success include the clinic's relationship with multiple community organizations and its emphasis on providing reproductive health information rather than just services during the visits.

While only 15 women sought services, more than three times that amount had informal discussions with the community outreach educator about contraceptive methods, STI testing, or other reproductive health topics. Enhancing the contraceptive knowledge of this population is particularly important because women with opioid and other SUD are less likely to use moderately or highly effective methods of contraception (18). This behavior may be explained by opioid-induced amenorrhea and resulting beliefs about infertility, and less autonomy about when sex occurs because of higher risk of being in a coercive relationship with men (including sex in exchange for drugs), and a higher prevalence of experiencing rape and sexual abuse (4).

Finally, there was high retention of community organization sites in the pilot program. This is likely due to the efforts of the clinic to identify relevant community organizations through discussions with persons involved in residential treatment centers and recovery programs and through their efforts to build connections with the community organizations well in advance of the pilot program launch.

\section{Opportunities to broaden the impact of the pilot program}

Deficiencies in the pilot program design may have limited its impact to roughly 2 telehealth patients per month over the six-month period. Having only one full time community outreach educator meant the number and geographic distance of the sites had to be confined to allow for multiple visits to each site per month. To increase the reach of this program, more community outreach educators would be needed to accommodate added sites. More sites might mean a higher volume of women with OUD seeking services, which would require more dedicated staff for telehealth services, oversight of lab results, referrals, and scheduling appointments at nearby family planning clinics.

During the pilot program, only three reproductive health services were offered, family planning, HIV/STI counseling and testing, and pregnancy testing and options counseling. However, one of the most requested service was hepatitis $\mathrm{C}$ testing. Maine ranks as having the ninth highest rate of acute hepatitis $\mathrm{C}$ in the nation (50); with recent increases being attributed to injection drug use (51), most commonly associated with heroin use (52). To provide hepatitis $\mathrm{C}$ testing would require implementing a standing 
order system that would allow the community outreach educator to test patients and order follow-up testing and referrals as needed.

Rates of non-attendance are high in OUD-supportive services (53). As such, each visit to a site placed community outreach educators into contact with new persons receiving services at the community organization. The tracking system used during the pilot program did not capture whether engagements or telehealth visits were performed with new persons or persons that were consistently attending the service program. Therefore, it is unclear whether the women who sought services through the telehealth system did so after repeated or singular exposure(s) to a community outreach educator. Capturing this information in a larger scale program will help determine whether the consistency of a community outreach educator on-site plays a role in telehealth service utilization. Additionally, these data will allow staff to keep track of new versus repeat patients and assess reproductive health care utilization patterns such as which patients are more apt to attend a follow-up appointment at a clinic and for what services.

Our finding that only forty percent $(n=2)$ of women attended their scheduled family planning clinic appointment highlights the fact that there are remaining barriers to health care utilization for this population. One limitation to the pilot program was that some women were using 'pay as you go' phone plans with insufficient airtime credits and/or were unable to receive voicemail. This meant that despite outreach efforts, some women did not receive an appointment reminder. To support the referral process, collecting multiple forms of contact information and working with participating community organizations to provide transportation to and from clinic appointments may improve women's ability to follow through with a referral. Given that referrals were for more involved sexual health services such as the insertion of a long-acting reversible contraceptive method, more work needs to be done to identify ways to facilitate access to these services.

Finally, no surveys or informative interviews were conducted with women who participated, informally or formally, in the pilot program, which was performed in the context of routine service delivery. As a result, there is a lack of information regarding what components of the program resonated the most with women, what improvements could be made, and what barriers remain to integrating reproductive health care services with supportive services for OUD at community organization sites. Further information on what additional services could improve participation, such as childcare and transportation is warranted.

\section{Conclusions}

A study of a pilot program that brings reproductive health care through telehealth to women with OUD in the rural state of Maine found that women were willing to engage with reproductive health services when co-located with OUD-supportive services (treatment, preventive, or social services). Telehealth allowed clinical staff from a family planning clinic to provide preventive reproductive health services such as HIV/STI counseling and testing and contraceptive care to this population. The benefit of this system is that it accommodates a population whose utilization of health care services is often diminished by perceptions of stigma and low self-efficacy. The success of this pilot program has led to the state designating funds to continue this program for another year. Lessons learned from the initial pilot program can be incorporated in other states and settings to ensure greater reach and impact of this novel health care delivery model.

\section{Acknowledgments}

The authors thank the family planning clinic staff who participated in this pilot program to provide reproductive services to women with OUD living in Maine, as well as Jessica Merrino of Ibis Reproductive Health for assistance with developing the figure included in this manuscript.

Funding: None.

\section{Footnote}

Provenance and Peer Review: This article was commissioned by the Guest Editors (Carinne Brody and Sarah Sullivan) for the series "Digital Interventions for Hard-to-reach Populations" published in mHealth. The article was sent for external peer review organized by the Guest Editors and the editorial office.

Conflicts of Interest: All authors have completed the ICMJE uniform disclosure form (available at http://dx.doi. org/10.21037/mhealth-19-237). The series "Digital Interventions for Hard-to-reach Populations" was commissioned by the editorial office without any funding or sponsorship. The authors have no other conflicts of interest to declare. 
Ethical Statement: The authors are accountable for all aspects of the work in ensuring that questions related to the accuracy or integrity of any part of the work are appropriately investigated and resolved.

Open Access Statement: This is an Open Access article distributed in accordance with the Creative Commons Attribution-NonCommercial-NoDerivs 4.0 International License (CC BY-NC-ND 4.0), which permits the noncommercial replication and distribution of the article with the strict proviso that no changes or edits are made and the original work is properly cited (including links to both the formal publication through the relevant DOI and the license). See: https://creativecommons.org/licenses/by-nc-nd/4.0/.

\section{References}

1. Kaiser Family Foundation. State Health Facts. Opioid overdose deaths and opioid overdose deaths as a percent of all drug overdose deaths. (January, 2019). Accessed, November 01, 2019. Available online: https://www.kff.org/ other/state-indicator/opioid-overdose-deaths/

2. National Institute on Drug Abuse (NIDA). Maine Opioid Summary. (March 2019). Accessed: November 01, 2019. Available online: https://www.drugabuse.gov/node/ pdf/21963/maine-opioid-summary

3. American Psychiatric Association. Addiction and Substance use disorders, Opioid Use Disorder. (November 2018). Accessed: November 01, 2019. Available online: https:// www.psychiatry.org/patients-families/addiction/opioiduse-disorder/opioid-use-disorder

4. Cornford CS, Close HJ, Bray R, et al. Contraceptive use and pregnancy outcomes among opioid drug-using women: a retrospective cohort study. PLoS One 2015;10:e0116231.

5. Heil SH, Jones HE, Arria A, et al. Unintended pregnancy in opioid-abusing women. J Subst Abuse Treat 2011;40:199-202.

6. Collier KW, MacAfee LK, Kenny BM, et al. Does colocation of medication assisted treatment and prenatal care for women with opioid use disorder increase pregnancy planning, length of interpregnancy interval, and postpartum contraceptive uptake? J Subst Abuse Treat 2019;98:73-7.

7. Fischbein RL, Lanese BG, Falletta L, et al. Pregnant or recently pregnant opioid users: contraception decisions, perceptions and preferences. Contracept Reprod Med 2018;3:4.

8. U.S. Department of Health and Human Services. Healthy
People 2020 Topics and Objectives: Family Planning. (November, 2019) Accessed: November 01, 2019. Available online: https://www.healthypeople.gov/2020/topicsobjectives/topic/family-planning

9. Mosher WD, Jones J, Abma JC. Intended and unintended births in the United States: 1982-2010. Natl Health Stat Report 2012;55:1-28.

10. Herd P, Higgins J, Sicinski K, et al. The implications of unintended pregnancies for mental health in later life. Am J Public Health 2016;106:421-9.

11. Haight SC, Ko JY, Tong VT, et al. Opioid Use Disorder Documented at Delivery Hospitalization - United States, 1999-2014. MMWR Morb Mortal Wkly Rep 2018;67:845-9.

12. Maeda A, Bateman BT, Clancy CR, et al. Opioid abuse and dependence during pregnancy: temporal trends and obstetrical outcomes. Anesthesiology 2014;121:1158-65.

13. Gabrielson, S. Maternal opioid use disorder at delivery hospitalization in a rural state: Maine 2009-2018. Oral presentation at the 2019 Northeast Epidemiology Conference in Portland, Maine, November 14.

14. Winkelman TNA, Villapiano N, Kozhimannil KB, et al. Incidence and Costs of Neonatal Abstinence Syndrome Among Infants With Medicaid: 2004-2014. Pediatrics 2018;141:e20173520.

15. Centers for Disease Control and Prevention. HIV and Substance Use in the United States. (November 2019). Accessed: November 19, 2019. Available online: https:// www.cdc.gov/hiv/risk/substanceuse.html

16. Centers for Disease Control and Prevention. Atlas Plus: HIV, Hepatitis, STD, TB, Social Determinants of Health Data. Accessed: April 2, 2020. Available online: https://gis. cdc.gov/grasp/nchhstpatlas/tables.html

17. Robinowitz N, Muqueeth S, Scheibler J, et al. Family Planning in Substance Use Disorder Treatment Centers: Opportunities and Challenges. Substance Use Misuse 2016;51:1477-83.

18. Terplan M, Lawental M, Connah MB, et al. Reproductive Health Needs Among Substance Use Disorder Treatment Clients. J Addict Med 2016;10:20-5.

19. United States Census Bureau. Growth in urban population outpaces rest of nation, Census Bureau reports 2012. Accessed: November 19, 2019 Available online: https:// www.census.gov/newsroom/releases/archives/2010_ census/cb12-50.html

20. Jones RK, Witwer E, Jerman J. Abortion incidence and service availability in the United States, 2017. New York: Guttmacher Institute, 2019. Available online: https:// 
www.guttmacher.org/report/abortion-incidence-serviceavailability-us-2017

21. Power to Decide. Health centers offering the full range of birth control methods, by state and county. (2019). Accessed: November 01, 2019. Available online: https:// powertodecide.org/what-we-do/access/birth-controlaccess

22. Bhagwan S, Williams TE, Landon MB, et al. A Critical Deficit of OBGYN Surgeons in the U.S by 2030. Surg Sci 2011;2:95-101.

23. Centers for Medicare and Medicaid services. Improving Access to Maternal Health Care in Rural Communities, issue brief. Accessed: November 01, 2019. Available online: https://www.cms.gov/About-CMS/Agency-Information/ OMH/equity-initiatives/rural-health/09032019-MaternalHealth-Care-in-Rural-Communities.pdf

24. Donovan M. Improving Access to Abortion via Telehealth. Guttmacher Policy Review 2019;22:23-8.

25. Field M. Telemedicine: A Guide to Assessing Telecommunications in Health Care. 1996.

26. Kohn JE, Snow J, Simons HR, et al. Medication Abortion Provided Through Telemedicine in Four U.S. States. Obstet Gynecol 2019;134:343-50.

27. Mehrotra A, Paone S, Martich D, et al. A comparison of Care at eVisits and Physician office visits for sinusitis and urinary tract infections. JAMA Intern Med 2013;173:72-4.

28. Gnirke A, Beckers SK, Gort S, et al. Analgesia in the emergency medical service: comparison between teleemergency physician and call back procedure with respect to application safety, effectiveness and tolerance. Anaesthesist 2019;68:665-75.

29. Hilty DM, Sunderji N, Suo S, et al. Telepsychiatry and other technologies for integrated care: evidence base, best practice models and competencies. Int Rev Psychiatry 2018;30:292-309.

30. Marcin JP, Ellis J, Mawis R, et al. Using Telemedicine to Provide Pediatric Subspecialty Care to Children with Special Health Care Needs in an Underserved Rural Community. Pediatrics 2004;113:1-6.

31. Maruschak L, Chari KA, Simon AE, et al. National Survey of Prison Health Care: Selected findings. Natl Health Stat Report 2016;96:1-23.

32. Hwang JS, Lappan CM, Sperling LC, et al. Utilization of Telemedicine in the U.S Military in a deployed setting. Mil Med 2014;179:1347-53.

33. Yang NH, Dharmar M, Yoo BK, et al. Economic Evaluation of Pediatric Telemedicine Consultations to Rural Emergency Departments. Med Decis Making
2015;35:773-83.

34. Grindlay K, Lane K, Grossman D. Women's and Providers' Experiences with Medical Abortion Provided Through Telemedicine: A Qualitative Study. Women's Health Issues 2013;23:e117-22.

35. Hantke N, Lajoy M, Gould CE, et al. Patient Satisfaction with Geriatric Psychiatry Services via Video Teleconference. Am J Geriatr Psychiatry 2020;28:491-4.

36. Baranowski MLH, Balakrishnan V, Chen SC. Patient Satisfaction with the Veteran's Administration Teledermatology Service. J Am Acad Dermatol 2019. doi: 10.1016/j.jaad.2019.01.036.

37. FH Healthcare Indicators and FH Medical Price Index. A new view of place of Service Trends and Medical Pricing. A FAIR Health White Paper, March 2018.

38. Castaño PM, Bynum JY, Andres R, et al. Effect of daily text messages on oral contraceptive continuation: a randomized controlled trial. Obstet Gynecol 2012;119:14-20.

39. Trent M, Thompson C, Tomaszewski K. Text messaging support for urban adolescents and young adults using injectable contraception: outcomes of the DepoText pilot trial. J Adolesc Health 2015;57:100-6.

40. Grossman D, Grindlay K. Safety of medical abortion provided through telemedicine compared with in person. Obstet Gynecol 2017;130:778-82.

41. Maine Shared Community Health Needs Assessment, County Health Profiles 2018 (page 26). Accessed: November 10, 2019. Available online: www.mainechna.org

42. Gavin L, Moskosky S, Carter M, et al. Providing quality family planning services: recommendations of CDC and the U.S. Office of Population Affairs. MMWR Recomm Rep 2014;63:1-54.

43. Pritchard IA. Searching for "Research Involving Human Subjects": What is Examined? What is Exempt? What is Exasperating? IRB: Ethics and Human Research 2001;23:5-13.

44. Hartzler B, Dombrowski JC, Crane HM, et al. Prevalence and Predictors of Substance Use Disorders among HIV Care Enrollees in the United States. AIDS and Behavior 2017;21:1138-48.

45. Grant BF, Stinson FS, Dawson DA, et al. Prevalence and co-occurrence of substance use disorders and independent mood and anxiety disorders: Results from the National Epidemiologic Survey on Alcohol and Related Conditions. Arch Gen Psychiatry 2004;61:807-16.

46. Thylstrup B, Clausen T, Hesse M. Cardiovascular disease among people with drug use disorders. Int J Public Health 
2015;60:659-68.

47. Morse S, Bride BE. Decrease in Healthcare Utilization and Costs for Opioid users following residential integrated treatment for co-occurring disorders. Healthcare 2017;5:54-60.

48. van Beek I. Case study: Accessible primary health careA foundation to improve health outcomes for people who inject drugs. Int J Drug Policy 2007;18:329-32.

49. Islam MM, Topp L, Day CA, et al. The accessibility, acceptability, health impact, and cost implications of primary healthcare outlets that target injecting drug users: A narrative synthesis of literature. Int J Drug Policy 2012;23:94-102.

50. Maine Center for Disease Control and Prevention. Acute Hepatitis C Maine Surveillance Report 2017. Accessed: November 17, 2019. Available online: https://www.

doi: $10.21037 /$ mhealth-19-237

Cite this article as: Thompson TA, Ahrens KA, Coplon L. Virtually possible: using telehealth to bring reproductive health care to women with opioid use disorder in rural Maine. mHealth 2020;6:41. maine.gov/dhhs/mecdc/infectious-disease/epi/hepatitis/ documents/2017-HCV-Acute-Surveillance-Report.pdf

51. Zibbell JE, Asher AK, Patel RC, et al. Increases in Acute Hepatitis C Virus Infection Related to a Growing Opioid Epidemic and Associated Injection Drug Use, United States, 2004 to 2014. Am J Public Health 2018;108:175-81.

52. Maine Center for Disease Control and Prevention. Hepatitis C Enhanced Surveillance Project- Maine, 2015. Accessed: November 17, 2019. Available online: https:// www.maine.gov/dhhs/mecdc/infectious-disease/epi/ hepatitis/documents/2015-HCV-EnhancedSurvReport.pdf

53. Milward J, Lynskey M, Strang J. Solving the problem of non-attendance in substance abuse services. Drug Alcohol Rev 2014;33:625-36. 